\title{
Construction management scheduling and control: The familiar historical overview
}

\author{
Ali Behnam ${ }^{1,}$, Toby Harfield ${ }^{2}$ and Russell Kenley ${ }^{3}$ \\ 1, 2, 3Swinburne University of Technology, PO Box 218, Hawthorn, Victoria, 3122, Australia \\ ${ }^{3}$ Unitec Institute of Technology, 139 Carrington Road, Mount Albert, Auckland 1025, New Zealand
}

\begin{abstract}
The paper suggests that 'management by exception' is an historical default control mechanism based on the perception of control as a static process. However, increasingly scholars claim that a dynamic and proactive systems model is a more effective form of project control. These findings are the result of an historical desktop research method that analysed content from a small sample of scheduling methods and control approaches found in online and university library resources. The concept of control has historically influenced both visualization and analytics of different scheduling methods for construction project management. This paper focuses on two control ideals; static and dynamic control mechanisms. The overview begins with the description of early graphical scheduling techniques: Gantt charts and Harmonogram. It continues with examples of contributors to scheduling and control that include: CPM, PERT, LOB, Flowline and Location Based Management. The finding of this simple history suggests that change is the constant element for project control mechanisms. An object-based digital environment such as the datarich building information modelling (BIM) appears to be continuing the change for new scheduling methods and control mechanisms.
\end{abstract}

\section{Introduction}

The problem of control has always been an important question for construction. The efforts toward development of control strategies historically have resulted in different scheduling approaches. During the second half of the 20th century, the emergence of computers and their rapid development from mainframe to personal enabled advances in scheduling visualization and more complex analytical methods.

This paper adopts an historical desktop research method using online and university library resources to explore the development of different scheduling methods and control approaches. The search was based on two levels of keywords which accessed documents published between 1962 and 2014. The first level included the terms: "scheduling" and "control". These materials were then searched for such terms as "CPM", "PERT", "line of balance" and "location-based management". A sample of articles, journal papers and books was chosen to represent a chronology of change.

This paper provides a simple description of these developments based on a simple but novel continuum model for control: from static to dynamic. A static form of control has been called "management by exception", whereas; proactive control is considered a "dynamic process". Scholars agree that the main tool for construction project control is through scheduling. Thus, this paper provides an overview of a small sample of scheduling methods that have made a contribution to the continual advancement of construction project control.

The balance of this paper is structured: Section 2 outlines the concept of management by exception with four different scheduling approaches for static control. Section 3 discusses the contributions to dynamic control through a pro-active scheduling and monitoring approach. The conclusion summarizes the scheduling contributions discussed and suggests the future trajectory of the project control continuum.

\section{Static control}

For construction management, control is an important process. According to Kenley and Seppänen [1] control is a "very practical concept-one which every parent intuitively understands. Control is the mechanism by which a system is monitored and its behaviour corrected to ensure that performance is as planned." (p.96).

Historically, management by exception is considered static form of control. In such a system, remedial action is only necessary when deviations from the original plan occur. In modern construction management processes, the main tool for project control is through scheduling. The schedule is an effort to visually and analytically put activities in a sequential model that leads to project completion. As would be expected, attempts at project control mechanisms have continually changed with the rapid advances in both computing availability and power

\footnotetext{
${ }^{\mathrm{a}}$ Corresponding author: abehnammanesh@swin.edu.au
} 
[2] which supports increasingly complex forms of scheduling.

\subsection{Graphical project representations}

A Polish professor, Karol Adamiecki, specialized in engineering, economics and management. He developed a more sophisticated bar chart scheduling technique. His methodology for work harmonization was based on a diagrammatic schedule called a Harmonogram. While his technique provides data such as bill of quantities, duration of work and their associated dates, the technique also charts movement of work through processes, improving efficiency by aligning production rates. This early efficiency methodology however, was only published in Polish and thus did not gain acceptance in countries such as the US with high levels of construction during all of the 20th century [2].

In Germany, another system of graphical work activities was in place by 1912 . This static sequencing chart again seems to have been used only for German speaking construction projects. The American, Henry L. Gantt is attributed with the introduction in 1917 of the bar chart that is commonly used for construction projects today [3]. Gantt charts are probably universally used to represent the organization of production and dominant communication of a time schedule. These charts provide a graphical representation of several activities (y-axis) plotted against time (x-axis). The period of execution for each activity is shown as bar on the time graph corresponding to the planned times of occurrence. Parallel to the planned period, the actual period of execution is plotted. Despite advantageous simplicity of the bar chart, it fails to illustrate the interrelationships of the activities in a project. Therefore, the consequence of variations in duration and sequencing of each activity cannot be identified [4]. As a result, this graphical technique is not linked to any basic analytical method representing project progress or production rate [5].

\subsection{CPM and PERT}

Computers played an important role in automation for project management in 1950's. Both the academy and industry put major efforts towards the development of analytical methods. In particular, the importance of an accurate project planning and control for military projects during the Cold War was driver for effective solutions.

The most important development was the KelleyWalker method which provided the mathematical model that was to become the basis for computer programs to able to manage major projects. James E. Kelley and Morgan Walker first developed RAMPS (Resource Analysis and Multi-Project Scheduling). They later introduced a project scheduling method that became known as the critical path method (CPM) [6]. The fundamental principle of this method is that sequences can be illustrated graphically. Project activities are represented by an arrow (thus termed 'activity on the arrow') and when the arrows are linked they show graphically the sequence in which the jobs in the project must be performed [7].

Parallel to development of CPM, the US Navy developed mechanisms to optimize production for more cost efficient military programs. The consulting firm of Booz, Allen and Hamilton was established in 1956 to progress the work started with the Special Projects Office of the US Navy. The result of the development efforts, PERT (program evaluation review technique) was designed for the Fleet Ballistic Missile Program; however, it was not much used by the Navy. PERT was initially aimed at forecasting the likelihood of project success for R\& D projects. This however, did not stop the growth of claims of successful project management using this method. Kelly and Walker [8] primarily were concerned with control through introducing a system for 'management by exception'. In such a system, management need only act when deviations from the original plan occur. On the other hand during early development of PERT, the US Navy reports acknowledged the necessity of control information to enhance the management system. But sales of a variety of network-based project management systems in the US, UK and Europe also were predicated on project control through 'management by exception' [9].

Management by exception is basically an 'after-thefact' approach to control. Deviations are investigated and only then remedial action is taken. This requires the intervention of the project manager to make a forecast of future actions [10].

This approach creates challenges for project managers because the duration of future activities in a project are not related to past activities of the same kind. In fact, CPM algorithm is not capable of forecasting future actions without altering future estimates of duration.

\subsection{Line of balance (LOB) method}

Line of Balance (LOB) was introduced as an alternative method to CPM in order to facilitate the balancing of repetitive operations based on a production scheduling technique. The main advantage of the method was its simple graphical format to obtain necessary information on production rate and duration of the tasks [11]. The aim of the LOB was to ensure that components or subassemblies are ready at the time they are required to meet the production schedule of the final assembly [12].

The technique originated as a way to handle repetitive construction found in both highways and high rise buildings. In early 1940, the Good Year Co. Ltd. Introduced the LOB method before US Navy started using it as a tool for monitoring the progress of military and industrial processes [13]. Line of Balance was presented as a technique for assembling and interpreting the progress data (stages of industrial processes) in a graphic form against time [14].

Fundamentally, the premise of this technique is defined as the determination of the production rate of finished products in an operation line [15]. This has three component outputs: 1) a unit network that illustrates the relationships and duration of activities; 2) an objective 
chart that shows the cumulative calendar of unit completions; 3 ). a progress chart depicting the detailed completion of each unit [16].

\subsection{Linear scheduling method and flowline}

A focus on CPM and PERT in early publications indicates significant success for these methods leading to their use in several well-known commercial software applications. However, there were doubts among some researchers about the suitability of these methods for linear and repetitive infrastructure projects. Some researchers realized that CPM and PERT failed to recognize the significance of work overflow and continuity. Over the years researchers have noted that network methods add little to solving the planning problem where there is significant proportion of repetition [11], [17-18].

Consequently, besides the application of LOB methodology on repetitive construction, particularly projects with discrete repetitive units, researchers were encouraged to develop a method to emphasize the repetition of tasks over a distance.

The earliest representation of this method was the time versus distance diagram [19]. Using this technique for linear projects, the work progress of activities in the project can be illustrated with better presentation of information. The production rate of an activity can also be determined by the slope of the plotted line on the timedistance diagram. There have been several popular representations for flow of work through distance and locations. The most important is derived from Selinger [20] his supervisor Peer [21] and Birrell [22].

The linear scheduling method utilized a diagram to graphically illustrate the location and time of each activity in the project over a distance. In this graphical representation, continuous activities completed over the distance are illustrated by lines consisting of a continuous set of points. Therefore, the location of work in progress can be determined at any point in time [23].

The focus of the Peer's representation was mainly on movement of crews which perform a set of activities in a fixed sequence. It is often stated that the Flowline is a graphical representation similar to LOB [24]. However, there are significant differences between these two methods. The main difference is that the LOB vertical axis represents the line of balance quantity, while vertical axis in Flowline represents location. The activities with slowest production rate (lowest slope) are considered as critical activities. Besides, other critical activities include those which control the start time of the slowest activity or are required to complete the project [9].

\subsection{Location-based thinking}

Birrell [22] is an early researcher who developed a model for flow of work through location. Unlike Flowline and time-distance diagram which were mainly used for linear project, his model emphasized the role of location in any construction projects including buildings. He focused on the consideration of work crews as a continuous flow along the locations of the project. He noted that this would minimize the complexity of construction process and the confusion of the participants as the work passes through various locations in a consistent sequence. This single sequence also enables project managers or the general contractor's site superintendent to build a rhythm of work and movements of work squads through projects. Birrell's model of repetitive construction considers three different physical locations in the project including vertical segmentation, horizontal segmentation and the space available within the site, but outside the building, for material storage and handling.

Birrell constructed a matrix of work packages with work locations on the vertical axis and time period on horizontal axis. He clearly used queuing theory to prepare the work for the construction crew. He identified the idea that the construction process is made up of many flow lines (queues) each consisting of each work squad moving through a series of locations. The scheduling techniques list above indicates that the extension of project management complexity as the development of computing hardware and software developed for application for construction management. However, the each of the construction processes that were identified remained locked within a concept of static or reactive project control [1], [25], [5].

\section{Dynamic control}

In a productive or dynamic control system, necessary actions are taken before deviations occur. The scheduling techniques based on this approach provide greater and more effective opportunities for project control. Subsection 3.1 to 3.3 outline the historical development of three important changes to project management scheduling that can be seen as instrumental in shifting project control from a static to a dynamic response to deviations. Learning has been identified as a major contributor considering the application of proactive scheduling possibilities. Monitoring probabilities for acceptable rates of productivity has also become a welcome form of pro-active control. In addition, location has been increasingly acknowledged as the foundation of learning and visual monitoring of deviations in all construction projects [26].

\subsection{Learning}

Peña-Mora, \& Li [5] provide a systems perspective concerning forward and backward movement of project control. To accomplish work they consider reliability that consists of three variables: learning effect on reliability, staff experience, and schedule pressure. Thus, learning becomes an important factor for working crews, the schedulers and the quality control of inspectors. The learning curve data provides evident monitoring information for proactive control through three processes of the production system.

\subsection{Continuous planning or control?}


Research on location-based control began in Finland three decades ago and resulted in major discussions about scheduling systems. The main deriver for this research was the rapid increase of cost of construction providing low profit margins for general contractors. As a result, three construction companies established a large research collaboration attempting to identify the main causes of their problem [27].

Research continued in the form of case studies research. Over 30 case studies were conducted and each brought some enhancement to the scheduling or control techniques [28]. The overall the outcome of these studies emphasized that control is more important than planning. In addition, good control requires continuous monitoring and immediate response to project deviations to reduce their impacts [28], [25]. Furthermore, effective control of construction projects based on calculations of sections and zones paved the way for development of a locationbased management system.

\subsection{Location based management (LBMS)}

Kenley and Seppänen [1] developed a system now commonly known as location-based management system (LBMS). In location-based scheduling and control methodology, a project is broken down into different location hierarchies. This makes a location-breakdown structure (LBS) which has many properties common with the work breakdown structure (WBS). In this methodology activities which are completed with continuous workflow through many locations are considered a single task. Task is the method of control and the container of data which relate to production of the project. Unlike the CPM algorithm, LBMS has the capability to ensure a smooth and continuous parade of crews from location to location with minimum idle time for workers and equipment.

Kenley and Seppänen [1] described a new locationbased control model which utilizes four stages of production information, each stage having its own schedule views, information, and properties. The stages are baseline, current, progress and forecasts. Locationbased scheduling provides enhanced visualization of work sequences, free locations and total impacts of deviations based on the progress stage as well as visual risk evaluations of schedules for control.

The location-based control system obviously focuses on location rather than activity in CPM to take necessary control actions based on visualization of any deviations before they occur. Scheduling and forecasts are based on data that includes the flow of resources between locations, location-based quantity data, production logic and learning experience from a location to location. Thus, the LBM has a dynamic control system that consequently facilities pro-active management, rather management by exception.

\subsection{LBMS and BIM}

According to Kenley and Harfield [29], "LBMS is an integrated network of management system components potentially involving all stages of construction, from design through to completion...a methodology for interacting with a BIM, placing demands on the BIM for both properties and characterization (breakdown)."

Location-based scheduling and control methodology is integrated with commercial software systems such as Vico office and Control. Vico Office provides reporting through $5 \mathrm{D}$ visualization $(3 \mathrm{D}+$ time$+\cos t)$. Vico Control allows for measurement of quantities, scheduling for lean production, forecasting and control [1].

\section{Conclusions}

For construction management, control is an important process. Historically, management by exception is considered a static form of control. This means that actions are only necessary when deviations from the original construction project plan occur. However, for productive and dynamic control, necessary actions are taken before deviations occur, taking into account the role of location, visualization, continuity of workflow and also process of learning throughout the project. The difference in philosophies between static and dynamic control historically resulted in development of different scheduling techniques.

The paper described project management control based on some details of five different scheduling approaches that developed in the 20th century. The transformation of scheduling practices was based on the growing complexity of both visualization and analytics.

The focus of visualization changed from activity to repetition, then distance and finally location as the unit of analysis for project scheduling that supports control mechanisms. On the other hand, the change in analytics in the different methods was influenced by the recognizing the importance of proactive control. Consequently, a static control approach shifted to a more effective practice of dynamic control with continuous visual monitoring and look-ahead scheduling.

Project management scheduling visualization and analytics for control are expected to continue their trajectory of continuous development. With the increasing adoption of building information modelling (BIM), the next big leap is integration within an objectbased digital environment. This provides the opportunity for new control tools, systems and models.

\section{Acknowledgement}

The Swinburne University of Technology MelbourneSarawak Research Collaboration Scheme ID number 3000004617 has funding for this research.

\section{References}

1. R. Kenley \& O. Seppänen, Location-based Management for Construction. New York: Spon Press (2010) 
2. P. Weaver, A brief history of scheduling (2006) Online:http://www.mosaicprojects.com.au/PDF_Pap ers/P042_History\%20of\%20Scheduing.pdf

3. P.B. Petersen, J. Mang. Issu. 3, 131-155 (1991) Online: http://www.jstor.org/stable/40603907

4. E. Chrzanowski \& D. Johnston, J. Constr. Eng. Manage.

Online: http://dx.doi.org/10.1061/(ASCE)07339364(1986)112:4(476)

5. F. Peña-Mora \& M. Li, J. Constr. Eng. Manage. Online: http://ascelibrary.org/doi/10.1061/(ASCE)07339364(2001)127:1(1)

6. F.K. Levy, G.L. Thompson \& J.D. Wiest, Harv.Bus. Rev. 41, 98-108 (1963)

7. J. Kelley, J. Indust. Sched. 21, 347-365 (1963)

8. J. Kelley, \& M. Walker, In Proceeding IRE-AIEE$A C M \quad$ '59 (Eastern) ACM digital library: http://dx.doi.org/10.1145/1460299.1460318

9. S. Perera, In Proceedings of IAHS Conference on Impact of Economy and Technology, 927-985 (1982).

10. J. Meredith \& S. Mantel, Project Management: A managerial approach. New York: John Wiley \& Sons (1995)

11. D. Arditi, \& M. Albulak, J. Constr. Eng. Manage. Online: $\quad$ http://dx.doi.org/10.1061/(ASCE)07339364(1986)112:3(411)

12. S. Suhail \& R. Neale, J. of Constr. Eng. and Manage. Online: http://dx.doi.org/10.1061/(ASCE)07339364(1994)120:3(667)

13. J. Lutz \& A. Hijazi, Constr. Manage. Econ., 11, 99110 (1993)

14. (ONM) Office of Naval Material, Line of Balance Technology (1962). Online: http://www.dtic.mil/dtic/tr/fulltext/u2/672029.pdf

15. Z. Al Sarraj, J. of Constr. Eng.Manage.Online: http://dx.doi.org/10.1061/(ASCE)07339364(1990)116:4(689)

16. R. Carr \& W. Meyer, J. Constr. Div. ASCE, Online: http://dx.doi.org/10.1061/(ASCE)CO.19437862.0001107

17. R. Reda, J. Constr. Eng. Manage. Online: http://dx.doi.org/10.1061/(ASCE)07339364(1990)116:2(316)

18. A. Russell \& W. Wong, J. Constr. Eng. Manage. Online: http://dx.doi.org/10.1061/(ASCE)07339364(1993)119:2(196)

19. L. Gorman, Rds. \& Sts. 115, 74-75 (1972)

20. S. Selinger, J. of the Constr. Div. ASCE Online: http://cedb.asce.org/cgi/WWWdisplay.cgi?9573

21. S. Peer, J. of the Constr. Div. ASCE, 100, 203-210 (1974)

22. G. Birell, J. Constr. Div. ASCE, 106, 389-407 (1980)

23. R. Harris \& P. Ioannou, J. Constr. Eng. Manage. Online: http://ascelibrary.org/doi/pdf/10.1061/(ASCE)07339364(1998)124:4(269)

24. P. Lumsden, The Line of Balance Method. London, UK: Pergamon Press (1968)

25. W. Alsakini, K. Wikstro \& J. Kiiras, Int. J. Proj. Manag. 22, 75-85 (2004)

26. R. Kenley \& T. Harfield, New Project Management
Models: Productivity Improvement for Infrastructure. Perth: SBENRC (2014)

27. O. Seppänen, Empirical research on the success of production control in building construction projects, Helsinki Finland: TKK Structural Engineering and Building Technology (2009)

28. J. Kiiras, A schedule and resource planning system for the implemenation phase of special projects, Helsinki Finland: Helsinki University of Technology. Construction Economics and Management Publications (1989)

29. R. Kenley \& T. Harfield, In Proc. of the Int. Conf. Constr. Chang. Wld. Online: http://www.irbnet.de/daten/iconda/CIB_DC27620.pd f (2014) 